\title{
HBIM MODELLING FOR AN HISTORICAL URBAN CENTRE
}

\author{
M. Avena ${ }^{1}$, E. Colucci ${ }^{2}$, G. Sammartano ${ }^{1,3}$, A. Spanò ${ }^{1,3, *}$ \\ ${ }^{1}$ Department of Architecture and Design (DAD), Polytechnic University of Turin, 10125 Turin, Italy - (marco.avena, \\ giulia.sammartano, elisabetta.colucci, antonia.spano)@polito.it \\ ${ }^{2}$ Department of Environmental, Land and Infrastructure Engineering (DIATI), Polytechnic University of Turin, 10125 Turin, Italy - \\ elisabetta.colucci@polito.it \\ ${ }^{3}$ Polito FULL | the Future Urban Legacy Lab, Toolbox coworking. Polytechnic University of Turin, 10134 Torino (Italy)
}

KEY WORDS: HBIM, Parametric modelling, multi-sensor 3D survey, UAV clouds, clouds segmentation, urban heritage, GIS-BIM visualisation.

\begin{abstract}
:
The research in the geospatial data structuring and formats interoperability direction is the crucial task for creating a 3D Geodatabase at the urban scale. Both geometric and semantic data structuring should be considered, mainly regarding the interoperability of objects and formats generated outside the geographical space. Current reflections on 3D database generation, based on geospatial data, are mostly related to visualisation issues and context-related application. The purposes and scale of representation according to LoDs require some reflections, particularly for the transmission of semantic information.

This contribution adopts and develops the integration of some tools to derive object-oriented modelling in the HBIM environment, both at the urban and architectural scale, from point clouds obtained by UAV (Unmanned Aerial Vehicle) photogrammetry.

One of the paper's objectives is retracing the analysis phases of the point clouds acquired by UAV photogrammetry technique and their suitability for multiscale modelling. Starting from UAV clouds, through the optimisation and segmentation, the proposed workflow tries to trigger the modelling of the objects according to the LODs, comparing the one coming from CityGML and the one in use in the BIM community. The experimentation proposed is focused on the case study of the city of Norcia, which like many other historic centres spread over the territory of central Italy, was deeply damaged by the 2016-17 earthquake.
\end{abstract}

\section{INTRODUCTION}

Integrating and harmonising the geometric and semantic component of $3 \mathrm{D}$ information management is an important research priority in various communities. Moreover, it is of high interest in many application fields related to urban space and built heritage knowledge that requires the exchanging and representation of 3D data and geo-information.

The BIM (Building Information Modelling) approach and the HBIM (Heritage BIM), which refers to built and cultural heritage, and the generation from cloud-based 3D survey techniques (scan-to-bim strategy), owes its more interesting aspects to object-based modelling (Murphy et al., 2013).

The literature has focused a lot on the geometric discretisation methods of the built heritage and the quality of the models and their reliability in representing the hierarchy and morphological complexity of many components (Banfi et al., 2018). On the other hand, many reflections on the semantic component have been raised, starting from the considerations on methods and formalisms for integrating heterogeneous information (De Luca, 2011). This investigation on geospatial data continued up to the most recent proposals to manage vocabularies, libraries of object and semantics, in the direction of mutual enrichment between BIM modelling and Geographic Informative Systems (Brumana et al., 2019).

On the other hand, reflections on the conceptual framework in geographic knowledge have been proposed to enhance differences in classifying real features (ontologies), multiscale issues, the mobility of objects, the many-to-many relationship of place names (gazetteers) and so on. (Laurini 2014).

This contribution's research questions try to develop some tools to originate object-oriented modelling in the HBIM environment. Both the urban and architectural scale, from point clouds obtained by UAV (Unmanned Aerial Vehicle) photogrammetry and TLS (Terrestrial laser scanning) 3D survey have been considered.

The experimentation is developed through the case study of the city of Norcia, in the centre of Italy, damaged by the 2016-17 earthquake.

According to the LOD (Level of Detail) and Lod (Level of Development), the work reflects the two modelling approaches of the object's geometry. The workflow starts from initial unstructured 3D data analysis and segmentation oriented to semantic modelling and proposes some considerations and test on automatic or semiautomatic clouds segmentation at different scales. Lastly, a further goal is to validate the storage of semantic information visualising HBIM models in GIS. A starting proposal of an ontological scheme supporting semantic conceptualisation of historical built heritage to generate parametric structured models from point clouds is applied to Norcia in (Colucci et al. 2021). The classes of objects of data models and the classification of the damages ascertained after the 2016 earthquake are the semantic information represented.

\section{FRAMEWORK}

There is no shortage of studies aimed at integrating relational databases with 3D models of architectural heritage obtained with BIM software (Roncella 2019).

The issues about data models and structuring and formats interoperability are certainly crucial tasks in the framework of urban scale 3D database generation, based on the use of geospatial data, both existing and newly generated.

A recent survey (Biljecki et al., 2015) returns to the predominance of the visualisation purpose of many examples of 3D city models, highlighting the effectiveness of use in many different fields of investigation. Simultaneously, the terminology is systematised by designing a taxonomy of requirements to define the elements of the 
inventory of 3D city models applications (semantic content, level of detail measured through LODs - Levels of detail, spatial coherence, etc.).

In the framework of geographic information standards, is known that IFC (Industry Foundation

Classes) (https://www.buildingsmart.org/standards/bsi-

standards/industry-foundation-classes/) and cityGML (City Geography Markup

Language) http://www.opengeospatial.org/standards/citygml), published by the Open Geospatial Consortium (OGC) are the two most prominent data models to represent digital city' object (Isikdag and Zlatanova, 2009).

$\mathrm{Xu}$ et. Al, (2014) perform a careful comparison of the object classes of the IFC standards and recognise that among the 900 available classes, at least 60-70 are characterised by a semantic representation very similar to the CityGML standard. They try to integrate the two standards to obtain city information modelling (CIM)

In terms of the integration of standards, the issues to be solved are complex. For this reason, shared studies have been launched on the conversion of BIM models into 3D city models, taking advantages of OGC CityGML and buildingSMART IFC as reference standards (Noardo et al., 2020). Other authors test the goal of integrating BIM models with ontological knowledge (Yang et al., 2019).

\subsection{A brief survey on LOD (CityGML), and LoG, LoI, LoD (IFC)}

This paragraph provides a quick study of LOD: in GIS, they are intended as Level of Detail and in BIM as Level of Development. CityGML LODs are subdivided in:

- LoD 0 is for regional and landscape level, it corresponds to the maximum generalisation, a $2 \mathrm{D}$ polygon represents the shape of a building.

- LoD 1 for the regional or city level (1:25000/1:10000 scale), the accuracy is low, the buildings are represented as volume, and the roofs are flat.

- LoD 2 for city district and urban context, (1:5000/ 1:1000 scale) the accuracy is medium. The buildings have roofs objects with their shape and orientation.

- LoD 3 for exterior architectural models (1:1000/1:500 scale) the accuracy is high. The buildings are represented in the actual form so as the roofs.

- LoD 4 enhance the previous LoD adding the interior architectural model (more than 1:500).

Further subgroups specifications enriching the general ones have been proposed to this original classification (Biljecki et al., 2016). BIM literature refers to Level of Geometry $(L o G)$ and to Level of Information (LoI) that are combined in LoD (Level of Development). $L o G$ refers to the graphical elements of the model, whilst $L o I$ refers to non-graphical information. Then, the research of Tolmer et al., (2013) suggests adopting a new vision of LOD with the meaning of Level of Decision. This means that depending on the different case study and the scope of the 3D representation the developer has to generate a digital model considering both LOD and LoD.

\section{METHODOLOGY}

\subsection{Goals}

Our main objective was to conduct the modelling phases in a comparative way, retracing the analysis of the point clouds through optimisation and segmentation, to finally trigger the objects modelling according to the LOD, comparing the one coming from CityGML and the one in use in BIM community.
Two different directions for objects modelling have been experimented combining two platforms: the first software tested is inserted in the so-called UrbanBIM domain, Autodesk ${ }^{\circledR}$ Infraworks 2018, able to host data from BIM and GIS platforms, to perform multiscale analyses on the urban fabric of Norcia, and to generate, starting from cartographic data, the remaining buildings of the city. The second parallel test used the popular Autodesk ${ }^{\circledR}$ Revit 2017 tool, starting from LOD2/LOD3 to final visualise in the BIM environment.

The following schema (Table 1) intends to synthesise the workflow that is designed to test and validate.

Table 1. The main step of the HBIM modelling workflow, involving point clouds segmentation and optimisation, and objects structuring according to LOD / LoD.

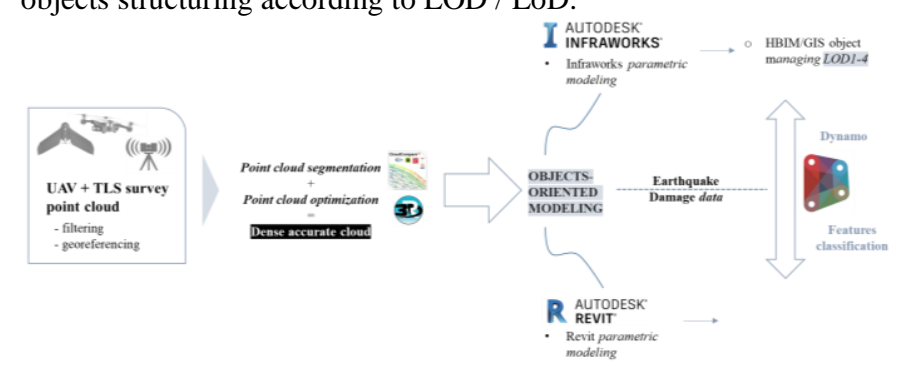

\subsection{Case study, UAV photogrammetry and TLS cloud data source}

The chosen case study is the city of Norcia, in the heart of the Valnerina territory at about $600 \mathrm{~m}$ asl. It was an Etruscan and also a Roman city, but it is above all later, in the Christian age, that Norcia assumes an essential role for being diocese, remembered for being the birthplace in the fifth century to San Benedetto, who reformed Christianity by founding the Benedictine order. The bond with the papal state was always pressing, constructing the most important architectural complexes, the city walls (XIII century) and the imposing basilicas of San Benedetto and San Francesco (XIV century) are due to the period in which Norcia was a free municipality.

The Apennine area of the Umbria region, in which continental tectonic plates meet, determines the high seismic risk of the area. Norcia has been hit repeatedly over the centuries by devastating earthquakes (the major ones in 1328, 1703, 1730 and 1859); the last that the application of this paper will document is the disastrous one of 2016-17 (Pagana, 2019).

With a magnitude of 6.5 , the most violent was that of $10 / 30 / 2016$, which caused numerous collapses of the churches and extensive damage.

This study' data derives from a 3D integrated documentation project of the city of Norcia carried out by the Geomatics group of the Turin Polytechnic in collaboration with the DIRECT team. It carried out training activities for students on 3D multisensor survey methods to generate multiscale and multicontents models in critical contexts. Integrated aerial and terrestrial approach delivered many kind of data. In this contribution, we focus mainly on multiscale photogrammetric data from UAV platforms. A nadir flight was performed for the entire historic city, using a fixed-wing drone (Ebee from SenseFly) with long-range; the flight altitude of about $120 \mathrm{~m}$ provided a GSD of about $4.3 \mathrm{~cm}$. The accuracy of the dense cloud following the GCP-optimized bundle adjustment and evaluated via CP is around $3-4 \mathrm{~cm}$. The overall point cloud is about 79 million points.

A much denser cloud was derived from a photogrammetric survey performed with the small and compact Spark DJI drone. A coordinated set of flights in nadir planning, with the camera 
axis at $45^{\circ}$ and orbital respectively on Piazza S. Benedetto di Norcia and on Castellina, allowed to obtain a GSD of about 1 $\mathrm{cm}$, an overall accuracy of a model between $1-2 \mathrm{~cm}$, and a total cloud of about 10 million points. This last cloud has been merged with another one even more detailed and dense, derived from the TLS survey carried out on the Castellina palace and the main square of Norcia (accuracy and resolution both few millimetres, $3-5 \mathrm{~mm}$, suitable for architectural documentation scale as usual of 1:50-1:100) (Figure 1).

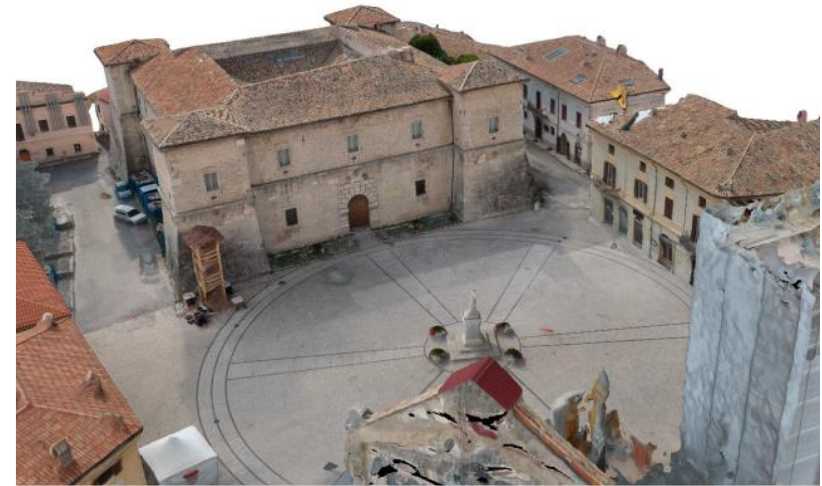

Figure 1. A detailed and accurate 3D mesh model derived from

UAV cloud of the San Benedetto square (Avena, 2020).

\subsection{From clouds to structured models}

Several segmentation approaches can be implemented when undertaking semantic modelling of heritage objects, especially considering the multiscale and multi-sensor nature of datasets. The potential of these unstructured point clouds lies in the richness of geometric and radiometric features associated with the continuity of 3D points characterising historical surfaces.

The filtering and optimisation phases are still semi-automatic. In opposition, the classification and the segmentation can benefit from algorithms implemented in clouds editing software GUI and large and complex datasets, such as machine and deep learning approaches (Matrone et al., 2020). The availability of intermediate annotated point clouds contributes to streamlining the workflow for semantic elements modelling toward HBIM systems within the parametric modelling workflow (Croce et al., 2021). In multiscale urban documentation, the more recent diffusion of mobile mapping systems based on multiple sensor fusion contributes providing a suitable point cloud dataset that is particularly configured to be annotated and segmented. The features analysis applied to historical structures, as ancient cities walls (Rodríguez-Gonzálvez, 2017) or fortress (Tucci et al., 2017) delivered promising results in terms of semantic components clustering. The recognition of homogeneity in specific features of the surfaces of the points (Grilli \& Remondino, 2019) allow designing automatic workflow to separate elements, label the elements (manually or with supervised learning) and reconstructs parametric shapes (Croce et al., 2021). The 3D supervised segmentation can be based on the combined use of 3D features related both to the geometric content and radiometric values continuity of the points, like edges- and region-based segmentation (region-growing families algorithms), or based on shape recognition by fitting geometry, like RANSAC-like approaches (Grilli \& Remondino, 2019).

In the case study of Norcia historic city, the geographic context related to the urban scale is firstly analysed and then the modelling will be more deepen for the architectural scale.

The transformation of DSM into DTM and object was employed to reconstruct the topography for the LOD1 modelling. Cloth Simulation Filter, CSF, implemented into Cloud Compare, CC Graphic User Interface, GUI (Zhang et al., 2016) has been applied to the UAV dense cloud in order to detect and separate terrain from urban objects. On the terrain dataset, one of the main goals was the automatic recognition of the great road that runs around the city walls. In the present case, since Norcia is a typical walled city and the road now replaces the ancient moat that once surrounded the city. The experimentation was conducted on the direction of automatic segmentation algorithm based on the recognition of points by homogeneity of radiometric values (Supervised colour segmentation, implemented in the 3Dreshaper ${ }^{\circledR}-3 D R$ by Leica Geosystems) (Figure 2).

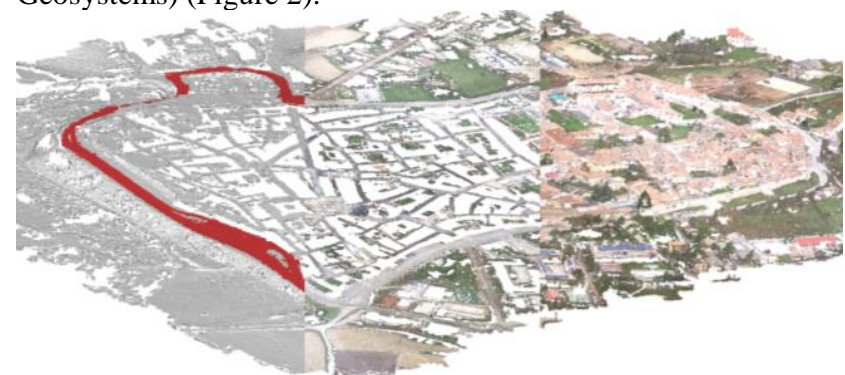

Figure 2. Urban scale cloud segmentation. From the left: DSM and DTM point cloud segmentation, road detection based on radiometric values.

In the second step, geometric features related to the building scale point clouds have been employed for the Castellina architectural elements segmentation (Figure 3). Concerning the dense cloud of the Norcia square, two different tools were tested that exploit the region growing algorithm, working on the surfaces normal, both implemented in the CC software and in $3 D R \circledR$ GUI. The results were quite different because of the walls local features. In the first case, the roofs was segmented from the buildings and the vertical walls were identified (figure 2a). In the second case the vertical parts of the walls of the Castellina were finally segmented concerning the scarp walls (figure $2 b$ ), using plane recognition, in 3DR® GUI.

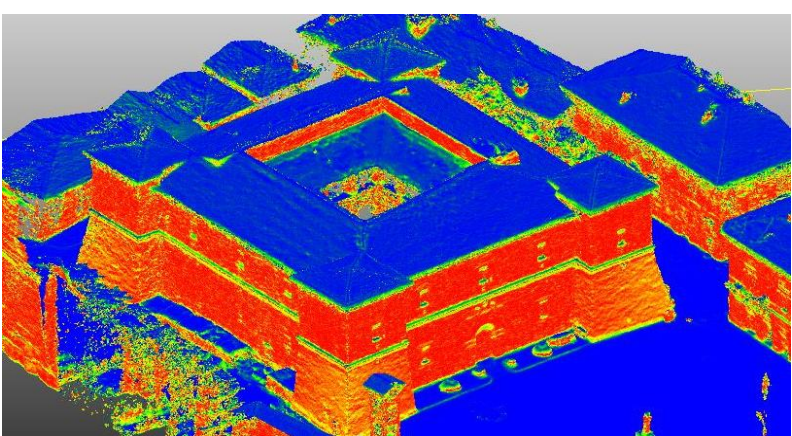

(a)

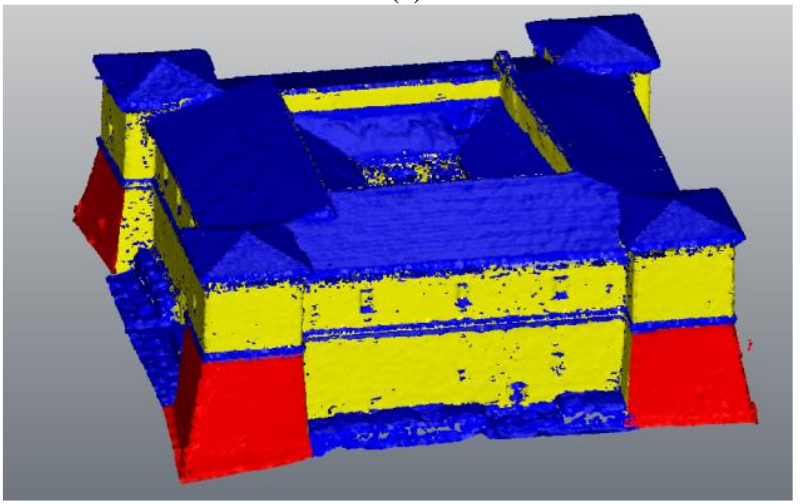

(b)

Figure 3. Architectural scale cloud segmentation. (a) Geomatric Feature, Verticality analysis. (b) the segmented point cloud. 


\section{OBJECTS MODELLING ACCORDING LODs}

\subsection{URBAN SCALE HBIM}

According to the multiscale approach adopted to provide the spatial information, the second phase of the work focused on HBIM modelling, which was organised according to the different LODs as regards both the additional priority of urban space documentation and the level of detail requested by the different degree of earthquake damage. For this reason, some building of San Benedetto square needed the higher attention in architectural morphology modelling (most of all the Castellina fortress that hosts a museum). Then, the level of details and development decrease gradually in a residential area in the southern part of Norcia that was completely evacuated, and then the rest urban area inside city walls.

In the following part, we present a description of the different LODs modelling whose contents are similar to the classification levels of development (in brackets) according to British Standards Institution (PAS 1192-2: 2013)

\section{LOD 0 modelling}

The starting point was a map in pdf format that the municipality of Norcia inserted in its published regulatory plan after the earthquake. It reports the result of a classification of the damage based on experts direct inspections according to the Italian legislation, which requires the compilation of the so-called AEDES (Agibilità e danno nell'emergenza sismica - usability and damage in seismic emergency) sheets. The map in Figure 4 represents the damage classification in GIS environment. The polygons of the buildings in the $2 \mathrm{D}$ cadastral database are encoded according to the damage scale. It is articulated from level A (absence of damage) to B, C, D, E (different level of damage that makes the building unusable due to intrinsic injury) and level $\mathrm{F}$ (the damage is due to the context). The content information related to this data should be integrated in the 3D modelling in GIS-BIM environments and assigned to buildings.

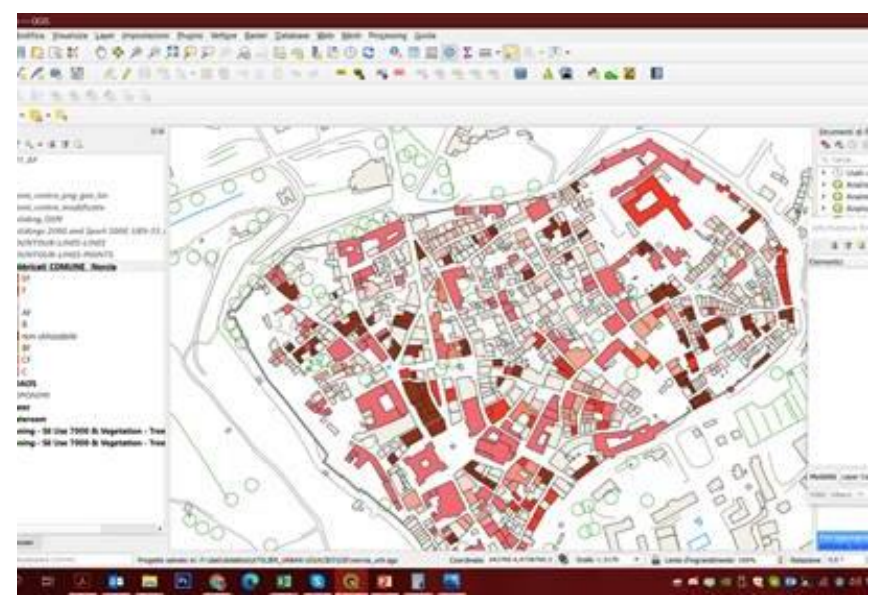

Figure 4. Level of usability due to seismic damage. Cadastral polygons are encoding.

- LOD 1 modelling (LoD 100)

As for the 3D model of the territory, Infraworks implements a specific digital models and satellite orthophoto from the Bing Map system using the Model Builder tool. For areas between $60^{\circ}$ and $+60^{\circ}$ longitudinal, in which Norcia is comprised, the DEM SRTM GL1 with an accuracy of $30 \mathrm{~m}$ is used (Bascones Recio 2018). Once the area under study has been selected and the correct geographic coordinate system (UTM WGS84-33N) has been set, the program automatically visualises other information of the territory divided by layers (volumetric buildings, roads, rivers, lakes, seas, etc.) from OpenStreetMaps. In the case of Norcia the DTM obtained from the UAV data, as described in paragraph 3.3, was used as terrain dataw. In Revit, it is not allowed to import digital models yet but only generate them. Then, the contours lines extraction have been conducted to perform the generation (Figure 5). Generic mass volume family of IFC standard have been used for buildings modelling as represented in Figure 6.
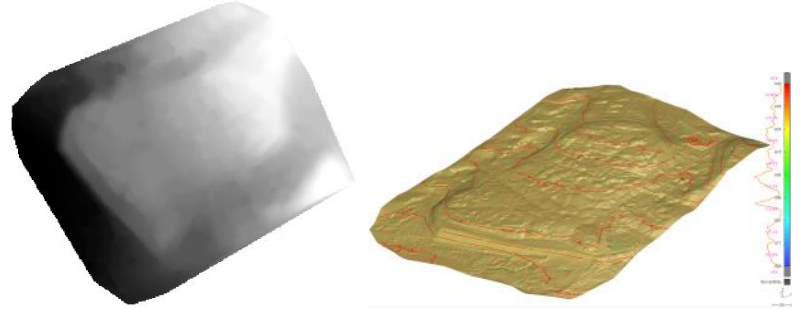

Figure 5. Digital terrain models used in HBIM modelling. (Left) DEM derived from UAV DSM. (Right) DEM generated from contours in Revit environment.

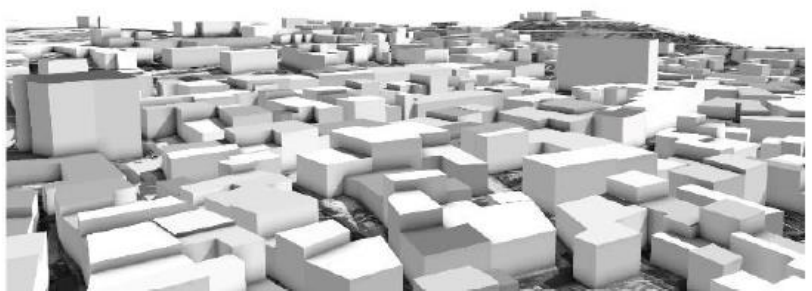

Figure 6. Representation of LoD 100 of Norcia in Infraworks environment.

\section{- LOD 2-3 (200-300)}

The urban morphology of Norcia is characterised by a typical medieval morphology as regards the buildings: the streets are very narrow and winding, while the buildings are compact and crowded together. In these particular areas, the eBee flight alone was able to acquire very accurate data from the nadiral shots, while as regards the information relating to the fronts of the buildings, lacks and imperfections were found. The buildings were therefore generated starting from simple overall geometries and their roofs.

LOD 2 (LoD 200) was used to identify buildings in a univocal way and at architectural scale, so using an higher level of detail. The openings (doors and windows) and the other construction elements from which they are composed have not been modelled ad hoc, avoiding to faithfully reproducing the real ones, but only generic elements similar to the originals (families) have been used.

In fact, if from a generic LOD 2 it is possible to obtain only data such as the shape, positioning and dimensions of a building, the more detailed geometric and semantic contents linked to a LOD 3 (300) instead guarantees more in-depth the features of the building organisms. Architectural choices, positioning doors and windows, roofs, identification of any imperfections or damage etc. are represented.

These buildings are mainly located in the area of Piazza San Benedetto and from the cloud of points sections and cloud front projections, elements such as doors, windows, balconies, any stairways, damaged or collapsed elements, etc. are visible and identifiable. Ultimately, the inclination of the pitches of the roofs was defined using appropriate sections of the point cloud, capable of unequivocally highlighting the profile of the natural roof. 
IFC object types in LOD 2 (LoD 200): ifcwall, ifc roof. IFC object types in LOD 3 (LoD 300): ifcWall, ifc Roof, ifcDoor, Ifcwindow, ifcstair.
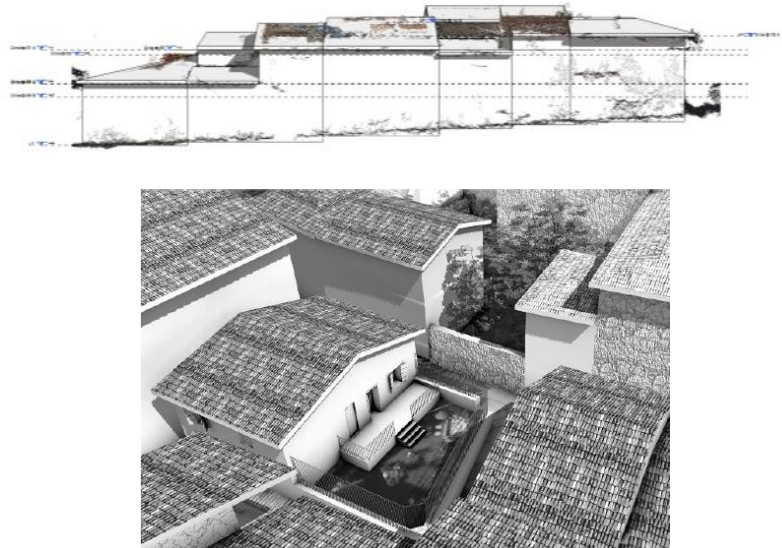

Figure 7. Examples of analysis of eaves, ridges and ground lines from building clouds, and corresponding modelling according to LoD 300 in the evacuated residential area.

\section{- LOD 4 (LoD 400)}

The richest and most accurate level of detail was achieved in accordance with the architectural detail level of the LiDAR cloud (capable of information content corresponding to the representation scale of 1: 100-1: 50). The construction elements modelling and details created specifically to represent the Castellina complex faithfully and in a certain way also the ruins of the basilica of San Benedetto (doors, windows, roofs, walls stratigraphic layers, decorations, internal portico).

This last LOD was reached using the Revit software, without the modelling of the internal environments, for which we did not have documentation and it.was not in any case among the refixed objectives.

The objects are classified according to a hierarchical and structured type, which bind them together and make them depend on each other. Such information can be visible, i.e. linked to geometric data useful for its graphic representation in a digital environment, or of a technical-informative nature and stored in the $\mathrm{db}$ object oriented system (materials, physical / mechanical / thermal / insulating properties of the individual components, economic data, times and costs etc.).

In addition to the object types of previous LoD 3, in the LoD 400 the property set of type and abjects have been added.

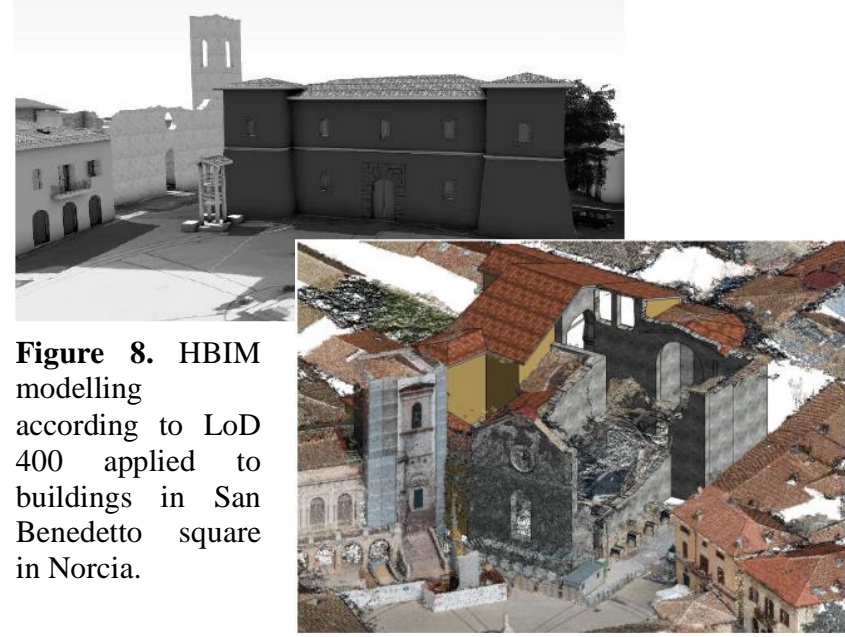

\subsection{HBIM models visualisation in GIS}

The integration of BIM models in GIS environment is a complex issue that request the conversion of IFC objects types in different geometric entities manageble in GIS environment. The literature reports many stratetegies and tests regarding BIM-GIS integration, so as some recent studies from Politecnico research group (Matrone et al. 2019, Colucci et al. 2020). Once the similarity in terms of richness of geometric details and semantic data among the LOD of the CityGml and the IFC standard has been predefined, as can be assessed from table 2 on the next page, our aim was to exploit the ability of visualisation interoperability of the ArcGIS Pro ESri software, to verify the preservation of geometric objects structuring and related information of the parametric models after the GIS visualisation.

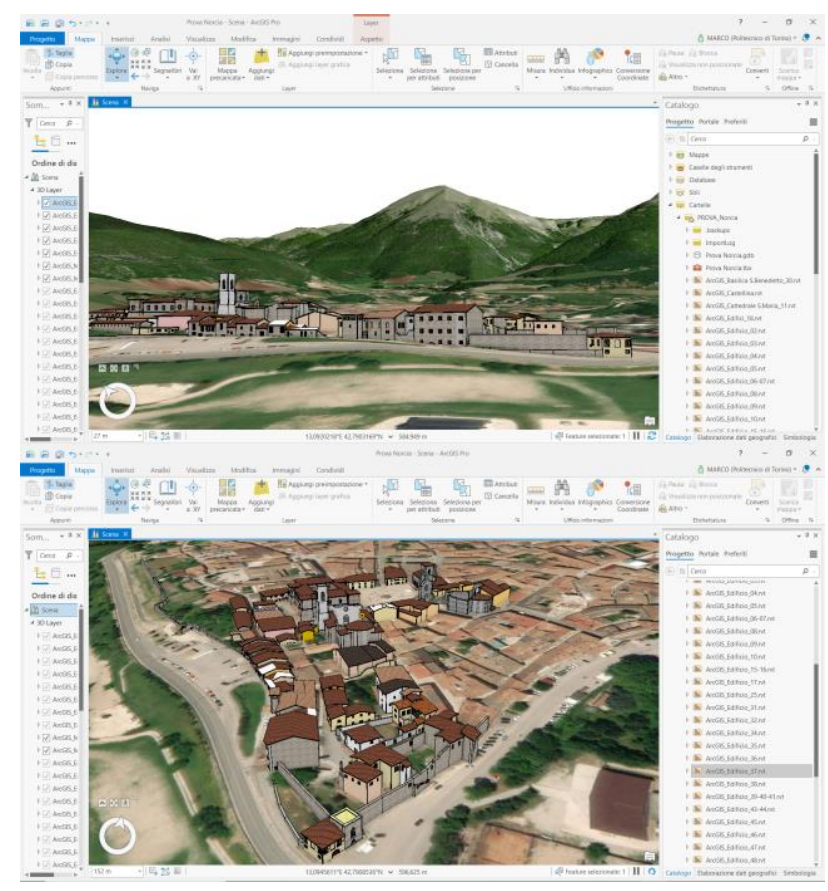

Figure 9. Visualisation of HBIM models in a 3D view of GIS environment.

\section{RESULTS AND DISCUSSION}

A first evaluation of the results of the test concerns the visualisation of objects generate by the BIM modelling. Although parametric modelling is proven to be more suitable for new constructions, the versatility of the modelling tools are adequate for the scenario of a city characterised by a historical building and architectural heritage. The derivation from the point clouds is undoubtedly time spending, but the result demonstrates a high capacity for describing the historical city.

The test carried out using two different platforms also highlighted how the use of Infraworks allows to streamline the way for the use of raster data models such as DEMs, typically featuring geographic information, and the management of geographical information reference systems.

As a further evaluation element, we decided to appraise the possibility of attributing the damage classification already available as an encoding of features included in the cadastral dataset to the HBIM models of buildings. 
Table 2. Existing similarities in the comparison of CityGML elements description and IFC objects definitions. We can notice a correspondence between the two different standards' LODs. Hence, in our methodology, the model designed according to IFC BIM has link/connection in the visualisation and in the scale of representation that could be noticed in the integration of the HBIM model in GIS.

\begin{tabular}{|c|c|c|c|c|c|}
\hline $\begin{array}{l}\text { CITYGML } \\
\text { ELEMENT/SURFA } \\
\text { CES }\end{array}$ & $\begin{array}{l}\text { CITYGML DEFINITION - } \\
\text { OGC City Geography Markup } \\
\text { Language (CityGML) Encoding } \\
\text { Standard - } 2012\end{array}$ & $\begin{array}{l}\text { IFC } \\
\text { ELEME } \\
N T / S O L \\
I D\end{array}$ & $\begin{array}{l}\text { IFC DEFINITION } \\
\text { (https://standards.buildingsmart.org/IFC/RELEASSE/IFC2x3/TC1/HTML/ifcshar } \\
\text { edbldgelements/ifcsharedbldgelements.htm\#entities) }\end{array}$ & $\begin{array}{l}\text { CITYGML } \\
\text { LOD }\end{array}$ & $\begin{array}{l}\text { IFC } \\
\text { LOD }\end{array}$ \\
\hline AbstractBuilding & $\begin{array}{l}\text { The pivotal class of the model is } \\
\text { _AbstractBuilding, which is a } \\
\text { subclass of the thematic class } \\
\text { _Site (and transitively of the } \\
\text { root class_CityObject). } \\
\text { _AbstractBuilding is specialised } \\
\text { either to a Building or to a } \\
\text { BuildingPart. }\end{array}$ & $\begin{array}{l}\text { Generic } \\
\text { Mass } \\
\text { Volume } \\
\text { family }\end{array}$ & - Volumetric model defining mass of buildings & LOD1 & LOD100 \\
\hline $\begin{array}{l}\text { RoofSurface } \\
\text { BuildingInstallation }\end{array}$ & $\begin{array}{l}\text { The major roof parts of a } \\
\text { building or building part are } \\
\text { expressed by the class } \\
\text { RoofSurface. Secondary parts of } \\
\text { a roof with a specific semantic } \\
\text { meaning like dormers or } \\
\text { chimneys should be modelled as } \\
\text { BuildingInstallation. }\end{array}$ & IfcRoof & $\begin{array}{l}\text { Definition from ISO 6707-1:1989: Construction enclosing the building from } \\
\text { above. } \\
\text { Definition from buildingSMART: The IfcRoof is a description of the total } \\
\text { roof. It acts as a container entity, that aggregates all components of the roof, } \\
\text { it represents. The aggregation is handled via } \\
\text { the IfcRelAggregates relationship, relating a roof (IfcRoof) with the related } \\
\text { roof entities, like slabs (IfcSlab), rafters and purlins (IfcBeam), or other } \\
\text { (included) roofs, such as dormers (IfcRoof). }\end{array}$ & LOD 2-3-4 & $\begin{array}{l}\text { LOD } 200 \\
\text { LOD } 300 \\
\text { LOD } 400\end{array}$ \\
\hline $\begin{array}{l}\text { WallSurface } \\
\text { InteriorWallSurface }\end{array}$ & $\begin{array}{l}\text { All parts of the building facade } \\
\text { belonging to the outer building } \\
\text { shell can be modelled by the } \\
\text { class WallSurface. } \\
\text { The class InteriorWallSurface } \\
\text { must only be used in the LOD } 4 \\
\text { interior building model for } \\
\text { modelling the visible surfaces of } \\
\text { the room walls. }\end{array}$ & IfcWall & $\begin{array}{l}\text { Definition from ISO 6707-1:1989: Vertical construction usually in masonry } \\
\text { or in concrete which bounds or subdivides a construction works and fulfils a } \\
\text { load bearing or retaining function. } \\
\text { Definition from buildingSMART: The wall represents a vertical construction } \\
\text { that bounds or subdivides spaces. Wall are usually vertical, or nearly vertical, } \\
\text { planar elements, often designed to bear structural loads. A wall is } \\
\text { however not required to be load bearing. The IFC specification provides two } \\
\text { entities for wall occurrences: }\end{array}$ & LOD 2-3-4 & $\begin{array}{l}\text { LOD } 200, \\
\text { LOD } 300 \\
\text { LOD } 400\end{array}$ \\
\hline Opening $\rightarrow$ Window & $\begin{array}{l}\text { The class_Opening is the } \\
\text { abstract base class for } \\
\text { semantically describing } \\
\text { openings like doors or windows } \\
\text { in outer or inner boundary } \\
\text { surfaces like walls and roofs. }\end{array}$ & $\begin{array}{l}\text { IfcWind } \\
\text { ow }\end{array}$ & $\begin{array}{l}\text { Definition from ISO 6707-1:1989: Construction for closing an opening, intended } \\
\text { primarily for access with hinged, pivoted or sliding operation. } \\
\text { Definition from buildingSMART: The door includes constructions with revolving } \\
\text { and folding operations. A door consists of a lining and one or several panels, } \\
\text { properties concerning the lining and panel are defined by } \\
\text { the IfcDoorLiningProperties and the IfcDoorPanelProperties. } \\
\text { - Definition form ISO } 6707-1: 1989 \text { : Construction for closing a vertical or near } \\
\text { vertical opening in a wall or pitched roof that will admit light and may admit } \\
\text { fresh air. } \\
\text { Definition from buildingSMART: A window consists of a lining and one or } \\
\text { several panels. Properties conceming the lining and panel(s) are defined by } \\
\text { the IfcWindowLiningProperties and the IfcWindowPanelProperties. }\end{array}$ & LOD3-4 & $\begin{array}{l}\text { LOD } 300 \\
\text { LOD } 400\end{array}$ \\
\hline BuildingInstallation & $\begin{array}{l}\text { The BuildingInstallation class is } \\
\text { used for building elements like } \\
\text { balconies, chimneys, dormers or } \\
\text { outer stairs, strongly affecting } \\
\text { the outer appearance of a } \\
\text { building }\end{array}$ & ifcStair & $\begin{array}{l}\text { Definition from ISO 6707-1:1989: Construction comprising a succession of } \\
\text { horizontal stages (steps or landings) that make it possible to pass on foot to } \\
\text { other levels. } \\
\text { Definition from buildingSMART: A vertical passageway allowing occupants } \\
\text { to walk (step) from one floor level to another floor level at a different } \\
\text { elevation. It may include a landing as an intermediate floor slab. }\end{array}$ & LOD3-4 & $\begin{array}{l}\text { LOD } 300, \\
\text { LOD } 400\end{array}$ \\
\hline- & - & $\begin{array}{l}\text { Constru } \\
\text { ctive } \\
\text { elements } \\
\text { stratigra } \\
\text { phy }\end{array}$ & $\begin{array}{l}\text { IfcBuildingElementPart represents major components as subordinate parts } \\
\text { of a building element. Typical usage examples include precast concrete } \\
\text { sandwich walls, where the layers may have different geometry } \\
\text { representations. In this case the layered material representation does not } \\
\text { sufficiently describe the element. Each layer is represented by an own } \\
\text { instance of the IfcBuildingElementPart with its own geometry description. }\end{array}$ & - & LOD400 \\
\hline
\end{tabular}

The diagram created in the open-source software Dynamo for Revit represents how visual programming can support assigning encodings to Norcia models respecting the relationship scheme established in the BIM database (Figure 10).
The table data containing the building damage codes are imported in the form of alphanumeric data. The attributes of the GIS environment are identified as "parameters" in the BIM environment and assigned through the identification codes as Shared Parameters to the conceptual masses representing the buildings. 


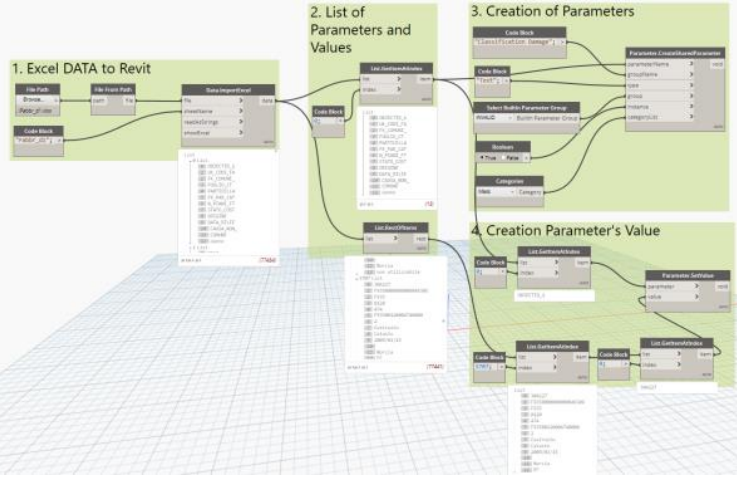

Figure 10. Dynamo visual scheme providing the assignment of damage codes to the Norcia buildings BIM models.

Once the damage identifier is linked through db relations to the building models, this information can be easily viewed by colouring the HBIM models, making the information easily perceptible to technical operators and stakeholders involved in the management of the complex phases of emergency management. Besides, in this case, if the identification codes have been correctly entered in the design phase of the HBIM, it can be demonstrated that the information can be easily connected in a highly automated form (Figure 11-12).

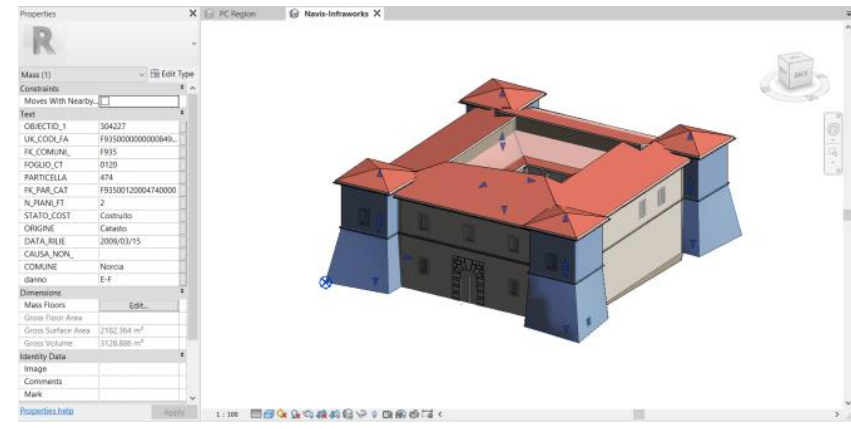

Figure 11. The results of the Dynamo assignment on the Castellina model.
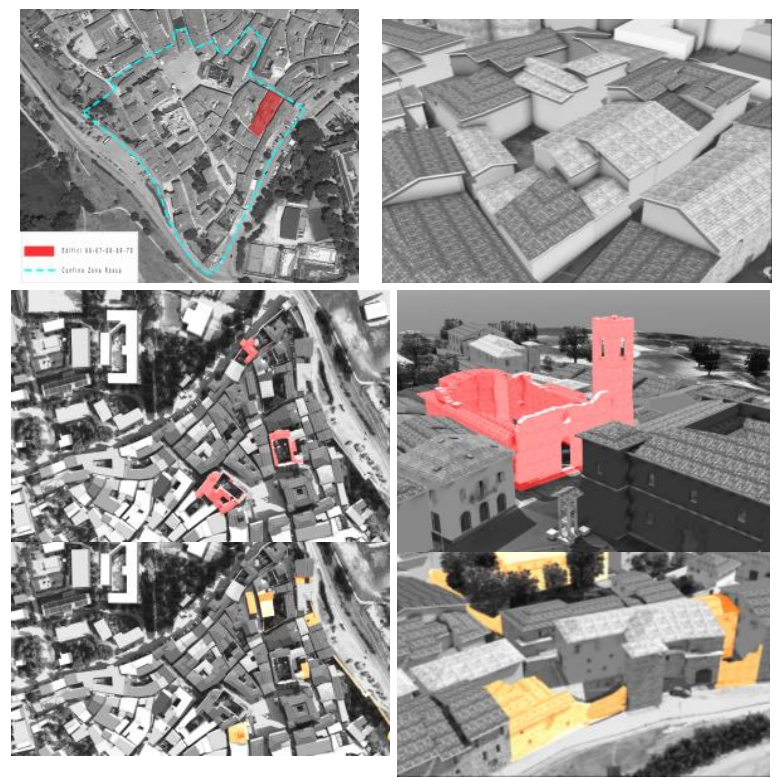

Figure 12. Classification of damage degree to the multiscale models of Norcia. (developed in LOD 2, 3 or 4)
Another important check occurs after the import of the HBIM models into the GIS environment for the possibility to visualyse not only geometry but semantid data.

Their internal structure is preserved as well as the semantic data related to its components (walls, openings, etc.). Figure 13 shows a query applied to the Castellina model in ArcGIS Pro environment, from the result of which it is possible to ascertain the level of usability $\mathrm{E}$, that is, unusable for intrinsic damage, plus the $\mathrm{F}$ code relating to the impossibility of use due to risk factors of the context.

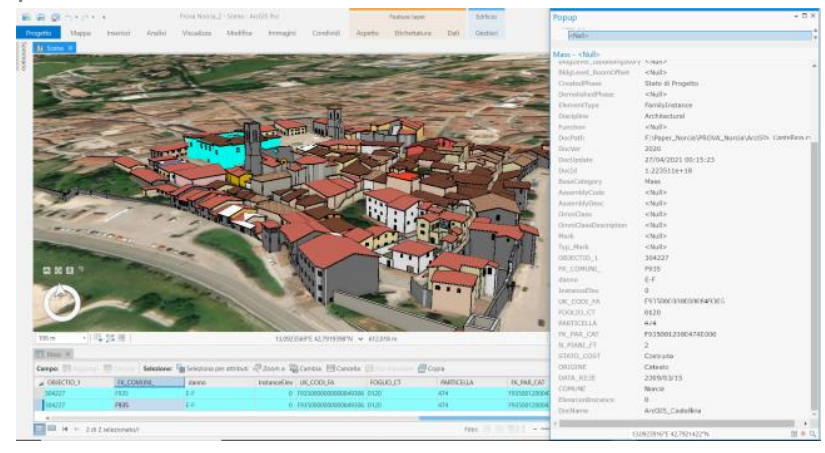

Figure 13. Storage of the geometric and semantic information in a HBIM model visualised in GIS environment.

\section{CONCLUSION}

The issues linked to the data structuring and formats interoperability are crucial tasks for creating a 3D database at the urban scale. In 3D geo-information science, 3D city models are based on the use of geospatial data and the most important objective is the harmonisation of different standards that allow a complete integration of BIM models in GIS environments.

It is also true that researches on this topic does not derive only from geoinformation science. Starting from satellite information, (Jackson \& Simpson 2020) retrace the most relevant innovations in the new mapping paradigms, the innovations in design and analysis in the field of constructions assisted by digital systems, in the standards for the so-called digital twinning which includes both the sphere of geographic information with the CityGM and the sphere of the parametric BIM paradigm.

It is not for coincidence that our work has attempted to probe the possibilities of representing urban space through HBIM modelling, as the urban heritage of historic cities can certainly take advantage of HBIM modelling starting from point clouds acquired through rapid $3 \mathrm{D}$ survey techniques such as UAV photogrammetry.

In this paper some issues concerning georeferencing and storage of the semantic enriched archive linked to parametric models visualised in GIS environment are commented and validated.

Retracing the workflow, the opportunities for both the use of the final solution that have to take charge of the management and maintenance policies of the city are considered, as well as the opportunities offered to professionals to obtain rich information archives through available tools.

\section{ACKNOWLEDGEMENTS}

The UAV and LiDAR data have been acquired during the onthe-field stage of team DIRECT students (https://www.g4ch.polito.it/wordpress/team-direct/). 


\section{REFERENCES}

Avena, M. (2020). Dalla Nuvola di Punti all'UrbanBIM Tecniche Integrate di Rilievo 3D per la Generazione di un Modello Multiscala di Città in Scenario Post Sismico. Il Caso Studio di Norcia (PG). Master's thesis, Politecnico di Torino, tutor A. Spanò, Turin, Italy.

Banfi F., Chow L., Reina Ortiz M., Ouimet C., Fai S. Building Information Modelling for Cultural Heritage: The Management of Generative Process for Complex Historical Buildings.,

Digital Cultural Heritage. Lecture Notes in Computer Science, 2018, vol 10605. Springer, pp. 119-130.

Bascones Recio, R. (2018). The Secret to Landscape Modelling whith InfraWorks, Autodesk Istructional Demo.

Biljecki, F., Stoter, J., Ledoux, H., Zlatanova, S., Çöltekin, A. (2015). Applications of 3D City Models: State of the Art Review. ISPRS Int. J. Geo-Inf. 2015, 4, 2842-2889.

Biljecki, F., Ledoux, H., \& Stoter, J. (2016). "An improved LOD specification for 3D building models", Computers, Environment and Urban Systems, 59, 25-37.

British Standards Institution. PAS 1192-2:2013. Specification for information management for the capital/delivery phase of construction projects using Building Information Modelling. 2013

Brumana R., Ioannides M., Previtali M. Holistic heritage building information modelling (HHBIM): From nodes to hub networking, vocabularies and repositories. In 2nd International Conference of Geomatics and Restoration, GEORES 2019, 2019, Vol. 42, No. 2, pp. 309-316.

Bruno N., Roncella R.. 2019. HBIM for Conservation: A New Proposal for Information Modelling. Remote Sens. 2019, 11.

Colucci, E., Xing, X., Kokla, M., Mostafavi, M.A., Noardo, F., Spanò, A. (2021). Ontology-Based Semantic Conceptualisation of Historical Built Heritage to Generate Parametric Structured Models from Point Clouds. Appl. Sci. 2021, 11, 2813. https:// doi.org/10.3390/app11062813

Colucci, E.; De Ruvo, V.; Lingua, A.; Matrone, F.; Rizzo, G. 2010. HBIM-GIS Integration: From IFC to CityGML Standard for Damaged Cultural Heritage in a Multiscale 3D GIS. Appl. Sci. 2020, 10, 1356. https://doi.org/10.3390/app10041356

Croce, V., Caroti, G., De Luca, L., Jacquot, K., Piemonte, A., \& Véron, P. (2021). From the Semantic Point Cloud to HeritageBuilding Information Modelling: A Semiautomatic Approach Exploiting Machine Learning. Remote Sensing, 13(3), 461.

De Luca, L., 2011. Methods, formalisms and tools for the semantic-based surveying and representation of architectural heritage, Applied Geomatics 6 (1866).

Grilli, E., \& Remondino, F. (2019). Classification of 3D Digital Heritage. Remote Sensing, 11(7), 847.

Isikdag U. and Zlatanova S (2009). Towards defining a framework for automatic generation of buildings in CityGML using building Information Models. 3D geo-information sciences, Springer: 79-96.

Jackson D. \& Simpson R. (2020), Digital City: An Urban Perspective on Digital Earth, in Guo, Goodchild, Annoni Editors, Manual of Digital Earth, Springer open, doi.org/10.1007/978-981-32-9915-3
Laurini, R. (2014). A conceptual framework for geographic knowledge engineering. Journal of Visual Languages and Computing, 25(1), 2-19. https://doi.org/10.1016/j.jvlc.2013.10.004

Matrone, F., Grilli, E., Martini, M., Paolanti, M., Pierdicca, R., \& Remondino, F. (2020). Comparing Machine and Deep Learning Methods for Large 3D Heritage Semantic Segmentation. ISPRS International Journal of Geo-Information.

Matrone, F.; Colucci, E.; De Ruvo, V.; Lingua, A.; Spanò, A. (2019). HBIM in a semantic 3D GIS database. Int. Arch. Photogramm. Remote Sens. Spat. Inf. Sci. 42, 857-865.

Murphy M, McGovern E, Pavia S., (2013). Historic Building Information Modelling -Adding intelligence to laser and image based surveys of European classical architecture, ISPRS J. Photogram. Remote Sensing, 2013, DOI: 10.1016/j.isprsjprs.2012.11.006.

Noardo, F.; Harrie, L.; Arroyo Ohori, K.; Biljecki, F.; Ellul, C.; et al.. Tools for BIM-GIS Integration (IFC Georeferencing and Conversions): Results from the GeoBIM Benchmark 2019. ISPRS Int. J. Geo-Inf. 2020, 9, 502.

Pagana, P., Sismicità storica in Umbria. Ricostruzione e studio dei principali terremoti verificatisi a partire dal III secolo a.C., 2013, Web Dic. 2019, Fonte: http://www.binapg.it/wpcontent/uploads/2013/11/Sismicità-storica-in-Umbria-elegislazione-in-materia-di-terremoti.modifica-7novembreottobre-.20135-copy.pdf

Rodríguez-Gonzálvez, P., Jiménez Fernández-Palacios, B., Muñoz-Nieto, Á., Arias-Sanchez, P., \& Gonzalez-Aguilera, D. (2017). Mobile LiDAR System: New Possibilities for the Documentation and Dissemination of Large Cultural Heritage Sites. Remote Sensing, 9(3), 189.

Yang, X., Lu, Y. C., Murtiyoso, A., Koehl, M., \& Grussenmeyer, P. (2019). HBIM modelling from the surface mesh and its extended capability of knowledge representation. ISPRS International Journal of Geo-Information, 8(7), 301.

Tolmer, C.-E., Castaing, C., Diab, Y., \& Morand, D. (2013). CityGML and IFC: Going further than LOD. 2013 Digital Heritage International Congress (DigitalHeritage), 1, 645-648. https://doi.org/10.1109/DigitalHeritage.2013.6743808

Tucci, G., Bonora, V., Conti, A., \& Fiorini, L. (2017). Digital Workflow for the Acquisition and Elaboration of 3D Data in a Monumental Complex: the Fortress of Saint John the Baptist in Florence. ISPRS - International Archives of the Photogrammetry, Remote Sensing and Spatial Information Sciences, XLII-2/W5(September), 679-686.

Zhang W, Qi J, Wan P, Wang H, Xie D, Wang X, Yan G. An Easy-to-Use Airborne LiDAR Data Filtering Method Based on Cloth Simulation. Remote Sensing. 2016; 8(6):501.

Xu, X; Ding, L;Luo, H; Ma, L; (2014) From building information modelling to city information modelling. Journal of Information Technology in Construction, 19 pp. 292-307 